SHUKLA, D.D.; WARD, C.W.; BRUNT, A.A.; BERGER, P.H. Potyviridae family. Descriptions of plant viruses, AAB, 1998.

THOLE, V.; DALMAY, T.; BURGYAN, J.; BALAZS, E. Cloning and sequencing of potato virus Y (Hungarian isolate) genomic RNA. Gene, v. 123, p. 149-561, 1993.

TORRES, A.C.; CANTLIFFE, D.J.; LAUGHNER, B.; BIENIEK, M. NAGATA, R.; FERL, R.J. Stable transformation of lettuce cultivar South Bay from cotyledon explants. Plant Cell, Tissue and Organ Culture, v. 34, p. 279-285, 1993.
TORRES, A.C.; NAGATA, R.T.; FERL, R.J.; CANTLIFFE, D.J.; BEWICK, T.A. In vitro assay selection of glyphosate resistance in lettuce. Journal of the American Society for Horticultural Science, v. 124, n. 1, p. 86-89, 1999.

TUMER, N.E.; O'CONNELL, K.M.; NELSON, R.S.; SANDERS, P.R.; BEACHY, R.N.; FRALEY, R.T.; SHAD, D.M. Expression of alfafa mosaic virus coat protein gene confers crossprotection in transgenic tobacco and tomato plants EMBO Journal, v. 6, p. 1181-1188;1987.
VAN DER VLUGT, R.; ALLEFS, S.; DE HAAN, P.; GOLDBACH, R. Nucleotide sequence of the 3'-terminal region of potato virus YN RNA. Journal of Genetic Virology, v. 70, p. 229-233, 1989.

WARD, C.W.; SHUKLA, D.D. Taxonomy of potyviruses: current problems and some solutions. Intervirology, v. 32, p. 269-297, 1991.

WEFELS, E.; SOMMER, H.; SALAMINI, F.; ROHDE, W. Cloning of the potato virus $\mathrm{Y}$ genes encoding the capsid protein $\mathrm{CP}$ and the nuclear inclusion protein NIb. Arch Virology, v. 107, p. 123-34,1989

SCHMIDT, D.; SANTOS, O.S.; BONNECARRÈRE, R.A.G; MARIANI, O.A.; MANFRON, P.A. Desempenho de soluções nutritivas e cultivares de alface em hidroponia. Horticultura Brasileira, Brasília, v. 19, n. 2, p. 122-126, julho 2.001.

\title{
Desempenho de soluções nutritivas e cultivares de alface em hidroponia ${ }^{1}$.
}

\author{
Denise Schmidt; Osmar S. Santos; Reinaldo Antonio G. Bonnecarrère; Odacir Antonio Mariani; Paulo \\ Augusto Manfron \\ UFSM. Depto. Fitotecnia - 97.105-900, Santa Maria - RS. E-mail: 9960006@alunop.ufsm.br
}

\section{RESUMO}

Foi conduzido um experimento em estufa plástica na Universidade Federal de Santa Maria (RS), com o objetivo de avaliar a eficiência de soluções nutritivas sobre a produtividade de cultivares de alface (Aurora, Lívia, Regina, Brisa, Mimosa e Verônica) em hidroponia. $\mathrm{O}$ experimento foi realizado no período de outubro a dezembro de 1998, em delineamento experimental de blocos ao acaso, com duas repetições. Avaliou-se sete soluções nutritivas recomendadas por Ueda na sua formulação completa; Castellane \& Araujo (50\% e $100 \%$ da concentração); Furlani (50\% e $100 \%$ da concentração); Bernardes (50\% e 100\% da concentração). Os resultados demonstraram que as soluções nutritivas completas, recomendadas por Castellane \& Araujo e Furlani foram as mais eficientes na produção de alface. A solução nutritiva Ueda apresentou a menor produtividade, mesmo quando comparada com as soluções diluídas (50\%). As cultivares Regina e Mimosa mostraram os melhores desempenhos e a cultivar Aurora mostrou pouca adaptação para cultivo nessa época do ano.

Palavras-chave: Lactuca sativa, cultivo sem solo, cultivo hidropônico.

\begin{abstract}
Efficiency of nutrient solutions and performance of lettuce cultivars in hydroponics.

The efficiency of seven different hydroponic solutions was evaluated on the yield of six lettuce cultivars (Aurora, Lívia, Regina, Brisa, Mimosa and Verônica). The experiment was performed from October to December 1998, in a randomized blocks designed with two replications. The nutrient solution recommended by Ueda was analyzed in its complete formulation (100\%), and Castellane \& Araujo; Furlani; and Bernardes in its complete and half formulation of nutrients concentration ( $100 \%$ and $50 \%)$. The nutrient solutions recommended by Castellane \& Araujo; and Furlani, without dilution (100\%), resulted in higher yield. The use of Ueda nutrient solution resulted in the lowest yield, even when compared with diluted solutions (50\%). Regina and Mimosa cultivars presented the best performance and Aurora the worst one.
\end{abstract}

Keywords: Lactuca sativa, soilless culture, hydroponic conditions.

\section{(Aceito para publicação em 09 de abril de 2.001)}

\begin{abstract}
$\mathrm{A}$ hidroponia é uma técnica de cultivo de plantas em meio líquido que tem se expandido no mundo todo como meio de cultivo de hortaliças, pois permite o plantio durante todo o ano, além de atender perfeitamente às exigências de produção com uniformidade, alta qualidade, alta produtividade, desperdício mínimo de água e nutrientes e o mí-
\end{abstract}

nimo uso de defensivos agrícolas (Alberoni, 1998).

No Brasil, a hidroponia está bastante disseminada. Em praticamente todos os Estados cultiva-se nesse sistema, principalmente a alface (Teixeira, 1996). Essa espécie é a mais difundida entre os produtores por se tratar de cultura de fácil manejo e por ter ciclo curto, garantindo rápido retorno do capital investido (Koefender, 1996). No mercado estão disponíveis muitas cultivares de alface, mas pouco se sabe a respeito de suas adaptações à hidroponia, não havendo recomendação de cultivares para esse sistema de cultivo (Gualberto et al., 1999).

Um aspecto fundamental para o sucesso do cultivo hidropônico é a esco-

\footnotetext{
${ }^{1}$ Parte da Dissertação de Mestrado em Agronomia da primeira autora, área de concentração em Produção Vegetal, pela Universidade Federal de Santa Maria (UFSM).
} 
lha da solução nutritiva, que deve ser formulada de acordo com o requerimento nutricional da espécie que se deseja produzir, ou seja, conter em proporções adequadas, todos os nutrientes essenciais para o seu crescimento. Atualmente existem diversas fórmulas recomendadas para o cultivo da alface. No entanto são poucas as informações sobre qual seja a melhor solução, pois elas apresentam grande diferença nas concentrações de nutrientes. Além disso, fatores como idade das plantas, época do ano e condições climáticas locais influenciam a eficiência da solução nutritiva (Faquin et al.,1996). Maroto (1990) afirma que, além da composição em si, deve-se considerar a concentração total da solução nutritiva, pois no verão, as soluções devem ser diluídas a até 50\%, quando comparadas com aquelas utilizadas no inverno.

Frente ao exposto, o presente trabalho teve como objetivo avaliar o desempenho de sete soluções nutritivas sobre a produtividade de seis cultivares de alface.

\section{MATERIAL E MÉTODOS}

O experimento foi conduzido em estufa plástica na UFSM, de outubro a dezembro de 1998.

$\mathrm{O}$ delineamento experimental utilizado foi o de blocos ao acaso, em esquema fatorial $7 \times 6$, com duas repetições, sendo que cada repetição foi composta pela média de quatro plantas úteis. As sete soluções nutritivas estudadas foram as recomendadas por Castellane \& Araujo (1995), Furlani (1995) e Bernardes (1997), preparadas com sua formulação completa (100\%) e com metade da concentração dos nutrientes $(50 \%)$ e a solução nutritiva recomendada por Ueda (1990) utilizada somente na formulação completa (100\%), por apresentar baixa concentração de sais. Avaliou-se, também, o desempenho de seis cultivares de alface, sendo três do grupo das lisas (Aurora, Lívia e Regina) e três do grupo das crespas (Brisa, Mimosa e Verônica).

A semeadura foi realizada no dia 9 de outubro de 1998, em bandejas de isopor com 288 células, preenchidas com substrato comercial (Plantimax). A seguir, as bandejas foram colocadas para flutuar em um sistema de piscina (floating), com lâmina de solução nutritiva de aproximadamente $5,0 \mathrm{~cm}$ de profundidade. Nessa fase, utilizou-se a solução nutritiva recomendada por Castellane \& Araujo (1995), diluída a $25 \%$.

Após 20 dias da semeadura, as mudas tiveram suas raízes lavadas, para retirada do torrão de substrato, e foram transplantadas para a bancada intermediária, denominada berçário, onde permaneceram por mais 12 dias. Nessa fase, a bancada de crescimento foi formada por uma telha de fibra de vidro, com canais de $3 \mathrm{~cm}$ de profundidade. Como forma de sustentação foram usadas placas de isopor, perfuradas no espaçamento de $10 \mathrm{~cm}$ entre plantas e $7 \mathrm{~cm}$ entre canais.

A seguir, as plantas foram transferidas para as bancadas definitivas, onde permaneceram até a colheita. $\mathrm{Na}$ fase final, as bancadas de cultivo foram formadas por telhas de cimento amianto com 3,66 m de comprimento, $1,10 \mathrm{~m}$ de largura e seis canais com $5 \mathrm{~cm}$ de profundidade, sendo impermeabilizados com tinta betuminosa (neutrol). Para o armazenamento das soluções nutritivas foram utilizados reservatórios de fibra de vidro com 400 litros. Desta forma o experimento foi composto por 14 bancadas com seis canais de cultivo cada uma e sete reservatórios de solução nutritiva, sendo que cada reservatório abastecia duas bancadas. O controle da circulação da solução nutritiva foi feito por temporizador programado para permanecer ligado por 15 minutos e desligado por 15 minutos, durante o dia (6:00 às 18:00 horas) e à noite (18:00 às 6:00 horas) 3 horas desligado e $15 \mathrm{mi}$ nutos ligado.

Como forma de sustentação das plantas nos canais de cultivo foi empregada pedra britada número 1 . O espaçamento usado foi de $25 \mathrm{~cm}$ entre plantas nos canais e $22 \mathrm{~cm}$ entre plantas de canais distintos. Cada cultivar foi distribuída em um canal, permanecendo deste modo 14 plantas em cada canal, totalizando 84 plantas por bancada.

Fez-se a correção do $\mathrm{pH}$, a cada dois dias, mantendo-o entre 5,8-6,2. Esta correção foi feita com $\mathrm{NaOH} 0,3 \mathrm{~N}$, para elevar o pH, ou então, com $\mathrm{H}_{2} \mathrm{SO}_{4} 10 \%$ para baixar o $\mathrm{pH}$. Semanalmente efetuouse a leitura da condutividade elétrica.
Durante o período em que as plantas permaneceram na bancada definitiva, a temperatura do ar no interior da estufa variou de $10^{\circ} \mathrm{C}$ a $37^{\circ} \mathrm{C}$, com média de $23^{\circ} \mathrm{C}$ e a umidade relativa do ar média foi de $60,5 \%$.

$\mathrm{O}$ experimento foi colhido quando as plantas atingiram 21 dias após o transplante para a bancada definitiva, totalizando ciclo de 53 dias. Os parâmetros avaliados foram número de folhas e massa de material fresco e seco da planta inteira (parte aérea e raízes). Os dados obtidos foram submetidos à análise de variância, sendo as médias comparadas entre si pelo teste de Tukey $(\mathrm{p}=0,05)$.

\section{RESULTADOS E DISCUSSÃO}

Houve interação significativa entre soluções nutritivas e cultivares para massa de material fresco de plantas (p£0,05). Analisando a Tabela 1, verificou-se que não ocorreram diferenças estatísticas entre as cultivares de alface nas soluções Castellane \& Araujo (1995) $100 \%$ e $50 \%$, Furlani (1995) $100 \%$ e $50 \%$, Bernardes (1997) 100\% e Ueda (1990). Apenas na solução nutritiva de Bernardes (1997) a 50\% as cultivares apresentaram desempenho diferenciado, razão principal da significância da interação. Na média geral, verificou-se que as soluções completas $(100 \%)$ apresentaram produção de massa de material fresco por planta maior quando comparadas com as soluções diluídas $(50 \%)$, pois continham maior concentração de nutrientes, representados pela condutividade elétrica (Figura 1). As soluções recomendadas por Castellane \& Araujo (1995) e Furlani (1995), sem diluição, apresentaram superioridade em relação às demais, mostrando as maiores produtividades. Das três soluções diluídas a Castellane \& Araujo (1995) apresentou pequena superioridade, diferindo estatisticamente da Bernardes (1997) e Furlani (1995), tendo todas atingido produtividade superior a $200 \mathrm{~g}$ planta $^{-1}$, enquanto a solução de Ueda (1990) mostrou a menor eficiência, tendo suas plantas apresentado a produtividade mais baixa, devido ao seu baixo conteúdo de sais (Tabela 1). As soluções nutritivas diluídas $(50 \%)$ resultaram em menor 
Tabela 1. Massa de material fresco de planta inteira $\left(\mathrm{g}_{\text {planta }}{ }^{-1}\right)$ de seis cultivares de alface produzidas com sete soluções nutritivas. Santa Maria, UFSM, 1998*.

\begin{tabular}{|c|c|c|c|c|c|c|c|c|}
\hline \multirow{2}{*}{ Cultivares } & \multirow{2}{*}{$\begin{array}{c}\text { Ueda } \\
100 \%\end{array}$} & \multicolumn{2}{|c|}{ Castellane \& Araujo } & \multicolumn{2}{|c|}{ Furlani } & \multicolumn{2}{|c|}{ Bernardes } & \multirow{2}{*}{ Média } \\
\hline & & $100 \%$ & $50 \%$ & $100 \%$ & $50 \%$ & $100 \%$ & $\mathbf{5 0} \%$ & \\
\hline Aurora & $115,2 \mathrm{a}$ & $267,1 \mathrm{a}$ & 179,6 a & $250,2 \mathrm{a}$ & $167,3 \mathrm{a}$ & $201,8 a$ & $147,1 \quad b$ & 189,8 \\
\hline Lívia & $106,0 \mathrm{a}$ & $274,2 \mathrm{a}$ & 199,6 a & $285,4 \mathrm{a}$ & 180,3 a & $264,1 \mathrm{a}$ & $197,3 \mathrm{a} b$ & 215,3 a b c \\
\hline Regina & 91,8 a & 316,8 a & $224,2 \mathrm{a}$ & $290,2 \mathrm{a}$ & 201,2 a & $236,2 \mathrm{a}$ & $191,6 \mathrm{a} \mathrm{b}$ & $221,7 \mathrm{a} \mathrm{b}$ \\
\hline Brisa & $111,1 \mathrm{a}$ & 244,0 a & $198,1 \mathrm{a}$ & 259,3 a & 187,5 a & $212,2 \mathrm{a}$ & 237,6 a b & 207,1 b c \\
\hline Mimosa & $132,7 \mathrm{a}$ & 299,7 a & $233,0 \mathrm{a}$ & $220,1 \mathrm{a}$ & 244,0 a & $273,8 \mathrm{a}$ & 268,9 a & 238,9 a \\
\hline Verônica & 83,6 a & 295,8 a & 203,4 a & $282,1 \mathrm{a}$ & $219,9 \mathrm{a}$ & 249,7 a & $191,2 \mathrm{a} \mathrm{b}$ & 218,0 a b c \\
\hline Média & $106,7 \mathrm{D}$ & $283,2 \mathrm{~A}$ & $206,4 \mathrm{~B}$ & $264,6 \mathrm{~A}$ & $200,0 \mathrm{C}$ & $239,6 \mathrm{~B}$ & $205,6 \mathrm{C}$ & 215,1 \\
\hline CV\% & & & & 12,1 & & & & \\
\hline
\end{tabular}

"Médias seguidas pela mesma letra, minúscula nas colunas e maiúscula na linha, não diferem entre si pelo teste de Tukey a 5\% de probabilidade de erro.

produtividade das plantas. Esses resultados contrariam os de Santos et al. (1998) que cultivando alface em vasos obtiveram bom desempenho com a solução Ueda (1990) em relação à recomendada por Castellane \& Araujo (1995), apesar de naquele estudo, a média da massa de material fresco por planta ser bastante inferior, em torno de 90,3 g para a solução de Castellane \& Araujo (1995) e 75,4 g para a solução recomendada por Ueda (1990).

Entre as cultivares, na média geral, verificou-se que Mimosa, Regina, Verônica e Lívia apresentaram maior produção de massa de material fresco. A cultivar Aurora apresentou a menor massa de material fresco e não diferiu significativamente da Brisa, Lívia e Verônica. A cultivar Aurora, também, emitiu pendão floral precocemente, mostrando sua pouca adaptação às condições de temperatura elevada que ocorreram durante o período de cultivo. Destaca-se, ainda, a cultivar Regina dentro da solução não diluída de Castellane \& Araujo (1995) que produziu plantas com a maior massa de material fresco do experimento ( $\left.316 \mathrm{~g} \mathrm{planta}^{-1}\right)$. Para a cultivar Verônica, esses resultados mostraram-se superiores aos encontrados por Koefender (1996) e Vaz \& Junqueira (1998) que, produzindo alface em sistema NFT, obtiveram, respectivamente, médias de 207,8 g e 183,4 g de massa de material fresco por planta. Faquin et al. (1996) obtiveram média de 385,5 g, porém cultivaram duas plantas por orifício. Já Mondin (1996) obteve resultado de massa de material fresco seme-

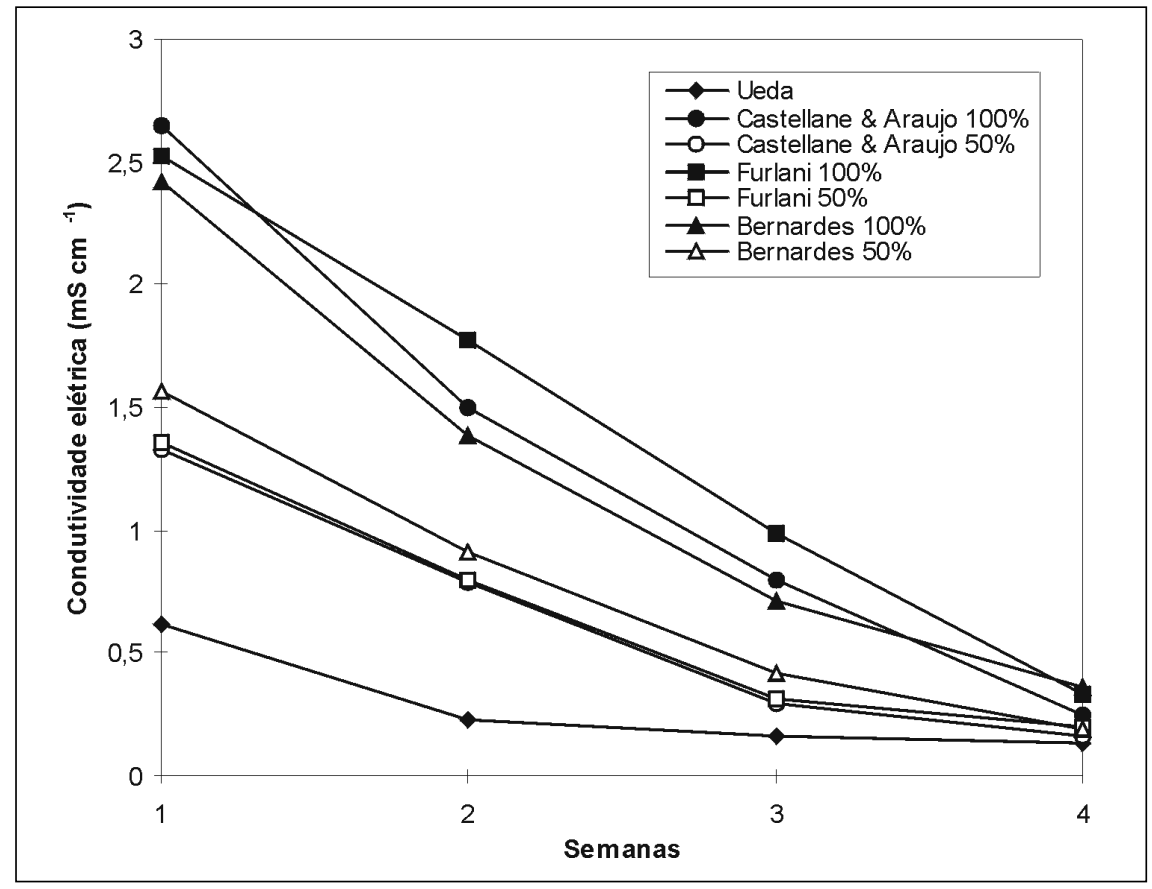

Figura 1. Condutividade elétrica de sete soluções nutritivas. Santa Maria, UFSM, 1998.

lhante ao deste estudo, encontrando média de $225,7 \mathrm{~g}$ por planta, observando-se, entretanto, que seu período de cultivo foi bem maior. Nogueira Filho (1999), estudando cultivares de alface em sistema NFT durante o período de inverno, obteve resultados semelhantes verificando que a cultivar Mimosa apresentou maior produção de massa de material fresco, com média de 237,7 g.

Analisando os dados da Tabela 2, verificou-se que a variável massa de material seco total não apresentou diferenças estatísticas para as diferentes soluções. Observou-se destaque da solução nutritiva diluída recomendada por
Furlani (1995), apesar desta não diferir estatisticamente das demais. Observouse ainda, que as soluções diluídas apresentaram médias mais elevadas, apesar de não diferirem estatisticamente das soluções completas. Essa tendência se justifica, porque nas soluções concentradas, ocorreu maior absorção de nutrientes (Figura 1) e, consequentemente, pelo efeito de osmose, ocorreu maior absorção de água. No momento de secagem das plantas, toda a água é retirada e as plantas produzidas nas soluções com maior concentração de sais perdem mais água, ficando com massa seca menor. Esses resultados são superiores 
Tabela 2. Massa de material seco de planta inteira $\left(\mathrm{g} \mathrm{planta}^{-1}\right)$ e número de folhas por planta de alface, produzidas em sistema hidropônico com sete soluções nutritivas. Santa Maria, UFSM, 1998

\begin{tabular}{lcc}
\hline \multicolumn{1}{c}{ Soluções } & $\begin{array}{c}\text { Massa de material } \\
\text { seco }^{1}\end{array}$ & Número de folhas \\
\hline Ueda 100\% & $12,55 \mathrm{a}$ & $20,3 \mathrm{c}$ \\
Castellane \& Araujo 100\% & $13,70 \mathrm{a}$ & $27,2 \mathrm{a}$ \\
Castellane \& Araujo 50\% & $14,84 \mathrm{a}$ & $26,7 \mathrm{a}$ \\
Furlani 100\% & $13,47 \mathrm{a}$ & $26,8 \mathrm{a}$ \\
Furlani 50\% & $14,99 \mathrm{a}$ & $26,5 \mathrm{a}$ \\
Bernardes 100\% & $14,18 \mathrm{a}$ & $25,3 \mathrm{a} \mathrm{b}$ \\
Bernardes 50\% & $14,92 \mathrm{a}$ & $24,4 \mathrm{~b}$ \\
\hline CV\% & 15,70 & 9,0 \\
\hline
\end{tabular}

*Médias seguidas pela mesma letra não diferem entre si pelo teste de Tukey a 5\% de probabilidade de erro.

${ }^{1}$ Média de seis cultivares.

Tabela 3. Massa de material seco de planta inteira $\left(\mathrm{g} \mathrm{planta}^{-1}\right)$ e número de folhas por planta de seis cultivares de alface, produzidas em sistema hidropônico. Santa Maria, UFSM, 1998.

\begin{tabular}{lcc}
\hline \multicolumn{1}{c}{ Cultivares } & $\begin{array}{c}\text { Massa de material } \\
\text { seco }\end{array}$ & Número de folhas \\
\hline Aurora & $12,76 \mathrm{~b}$ & $29,0 \mathrm{~b}$ \\
Lívia & $14,38 \mathrm{a} \mathrm{b}$ & $29,1 \mathrm{~b}$ \\
Regina & $13,36 \mathrm{a} \mathrm{b}$ & $34,4 \mathrm{a}$ \\
Brisa & $15,51 \mathrm{a}$ & $22,3 \mathrm{C}$ \\
Mimosa & $14,78 \mathrm{a} \mathrm{b}$ & $18,9 \mathrm{~d}$ \\
Verônica & $13,77 \mathrm{a} \mathrm{b}$ & $18,1 \mathrm{~d}$ \\
\hline CV\% & 15,70 & 9,0 \\
"Médias seguidas pela mesma letra não diferem entre si pelo teste de Tukey a 5\% de proba- \\
bilidade de erro. \\
${ }^{1}$ Média de sete soluções nutritivas.
\end{tabular}

aos encontrados por Santos et al. (1998), que obtiveram, em vasos, respectivamente, média de 4,70 g e 4,10 g para as soluções Castellane \& Araujo (1995) e Ueda (1990).

Com relação ao número de folhas por planta, não houve efeito significativo para a interação soluções nutritivas e cultivares. Na Tabela 2, observa-se que as soluções nutritivas Castellane \& Araujo (1995) 100\%, Furlani (1995) $100 \%$, Castellane \& Araujo (1995) 50\%, Furlani (1995) 50\%, Bernardes (1997) $100 \%$, apresentaram resultados semelhantes entre si. A solução Ueda (1990) apresentou o pior desempenho, diferindo significativamente de todas as outras soluções, em razão da baixa concentração de sais (Figura 1).

Para a produção de massa de material seco total (Tabela 3), verificou-se tivares Lívia e Aurora. As cultivares Verônica e Mimosa apresentaram as menores médias para este parâmetro. Verificou-se que as cultivares do tipo lisa apresentaram maior número de folhas que as cultivares do tipo crespa. Esses resultados são superiores aos de Vaz \& Junqueira (1998) que obtiveram 13,3 folhas por planta, mas foram inferiores aos de Mondin (1996) que obteve 29,6 folhas por planta. Nogueira Filho (1999) em estudo com cultivares de alface em sistema NFT, no período de inverno, observou tendência semelhante para cultivares, sendo que a 'Regina' apresentou o maior número de folhas por planta.

Os resultados demonstraram que as soluções nutritivas recomendadas por Castellane \& Araujo (1995) e Furlani (1995), sem diluição (100\%) foram as mais eficientes na produção de alface. De forma geral, todas as cultivares apresentaram bom desempenho no cultivo hidropônico, com exceção da cultivar Aurora que apresentou tendência ao pendoamento precoce nesta época do ano, quando as temperaturas são mais elevada.

\section{LITERATURA CITADA}

ALBERONI, R.B. Hidroponia - como instalar e manejar o plantio de hortaliças dispensando o uso do solo. São Paulo: Nobel, 1998. 102 p.

BERNARDES, L.J.L. Hidroponia da alface - uma história de sucesso. Charqueada: Estação Experimental de Hidroponia "Alface e Cia", 1997. 135 p.

CASTELLANE, P.D. ARAUJO, J.A.C. Cultivo sem solo - Hidroponia. $4^{\mathrm{a}}$ ed. Jaboticabal: FUNEP, 1995. $43 \mathrm{p}$.

FAQUIN, V; FURTINI NETO, A.E.; VILELA, L.A.A. Produção de alface em hidroponia. Lavras: UFLA, 1996. $50 \mathrm{p}$.

FURLANI, P.R. Cultivo da alface pela técnica de hidroponia - NFT. Campinas: Instituto Agronômico, 1995. 18 p. (Documentos IAC, 55).

GUALBERTO, R.; RESENDE, F.V.; BRAZ, L.T. Competição de cultivares de alface sob cultivo hidropônico 'NFT' em três diferentes espaçamentos. Horticultura Brasileira, Brasília, v. 17, n. 2, p. 155-158, jul. 1999.

KOEFENDER, V.N. Crescimento e absorção de nutrientes pela alface cultivada em fluxo laminar de solução. Piracicaba: ESALQ, 1996. 85 p. (Dissertação mestrado).

MAROTO, J.V. Elementos de horticultura general. Madrid: Ediciones Mundi-Prensa. 1990. 443 p.

MONDIN, M. Efeito de sistema de cultivo na produtividade e acúmulo de nitrato em cultivares de alface. Jaboticabal: UNESP, 1996. 88 p. (Dissertação mestrado) 
NOGUEIRA FILHO, H. Cultivares de alface $e$ formas de sustentação das plantas em cultivo hidropônico. Santa Maria: UFSM, 1999. 60 p. (Dissertação mestrado).

SANTOS, O.; MANFRON. P.; MENEZES, N.; OHSE, S.; SCHMIDT, D.; MARODIN, V. NOGUEIRA, H.; VIZZOTTO, M.. Cultivo hidropônico da alfaceITeste preliminar de soluções nutritivas. Santa Maria: UFSM, 1998. 7 p. (Informativo Técnico, 02/98).
SILVA, J.B.C.; CAÑIZARES, K.A.L.; NAKAGAWA, J. Efeito de níveis de cobre em alface cultivada em solução nutritiva. Horticultura Brasileira, Brasília, v. 14, n. 2, p. 226-228, nov. 1996.

TEIXEIRA, N.T. Hidroponia: uma alternativa para pequenas áreas. Guaiba: Agropecuária, 1996. $86 \mathrm{p}$.
UEDA, S. Hidroponia: guia prático. São Paulo: Agroestufa, 1990. $50 \mathrm{p}$.

VAZ, R.M.R. JUNQUEIRA, A.M.R. Desempenho de três cultivares de alface sob cultivo hidropônico. Horticultura Brasileira, Brasília, v. 16, n. 2, p. 178-180, nov. 1998.

RESENDE, G. M.; SOUZA, R.J. Doses e épocas de aplicação de nitrogênio sobre a produtividade e características comerciais do alho. Horticultura Brasileira, Brasília, v. 19, n. 2, p. 126-129, julho 2.001.

\title{
Doses e épocas de aplicação de nitrogênio sobre a produtividade e carac- terísticas comerciais de alho.
}

\author{
${ }^{1}$ Geraldo M. Resende; ${ }^{2}$ Rovilson José Souza \\ ${ }^{1}$ Embrapa Semi-Árido, C. Postal 23, 56.300-000 Petrolina-PE; UFLA, C. Postal 37, 37.2000-000 Lavras-MG. E.mail: gmilanez@ufla.br
}

\section{RESUMO}

O trabalho foi conduzido no período de abril a outubro de 1991, no Campo Experimental da Universidade Federal de Lavras para avaliar a influência de doses de nitrogênio e épocas de aplicação sobre a produtividade e características comerciais do alho (Allium sativum L.). Utilizou-se o delineamento de blocos ao acaso no esquema fatorial 5 x 3, compreendendo cinco doses de nitrogênio (40; $60 ; 80 ; 100$ e 120 kg/ha de N) e três épocas de aplicação (30; 50 e 70 dias após o plantio (dap)) e 3 repetições. O nitrogênio e as épocas de aplicação, atuaram independentemente sobre a produtividade total, observando-se efeito linear com o aumento das doses de nitrogênio e épocas de aplicação. Houve redução na produtividade comercial com o aumento das doses de nitrogênio. A dose de $\mathrm{N}$ de $40 \mathrm{~kg} / \mathrm{ha}$ proporcionou as maiores produtividades comerciais independentemente se aplicado aos $30 \mathrm{dap}(5.076 \mathrm{~kg} / \mathrm{ha}), 50 \mathrm{dap}(5.502 \mathrm{~kg} / \mathrm{ha})$ ou 70 dap após o plantio (4.086 kg/ha). A aplicação em cobertura mais tardiamente (70 dap) propiciou, de forma geral, as menores produtividades comerciais. Com o aumento das doses de nitrogênio, em função das épocas de plantio, verificou-se aumento linear na percentagem de bulbos pseudoperfilhados, sendo que a dose de $\mathrm{N}$ de 40 $\mathrm{kg} / \mathrm{ha}$ e aplicações aos 30 dap (30,6\%); 50 dap (34,9\%) e 70 dap $(42,0 \%)$, apresentaram as menores percentagens de bulbos pseudoperfilhados. Com a dose de $\mathrm{N}$ de $120 \mathrm{~kg} / \mathrm{ha}$ aplicada aos 30; 50 e 70 dap a incidência de bulbos pseudoperfilhados foi $65,2 \%$; $68,8 \%$ e $64,8 \%$, respectivamente. Para peso médio de bulbo observou-se efeitos lineares para doses de nitrogênio e épocas de aplicação, assim como constatou-se aumento no número de bulbilhos por bulbo, com o incremento das doses de nitrogênio.

Palavras-chave: Allium sativum L., rendimento, pseudoperfilhamento, peso médio de bulbo, número de bulbilho por bulbo.

\begin{abstract}
Influence of nitrogen rates and application time over yield and commercial characteristics of garlic.

We evaluated the influence of nitrogen rates and application time on garlic (Allium sativum L.) yield and marketable traits. The experiment was carried out from April to October 1991, in Lavras, Minas Gerais State, Brazil, in a randomized complete blocks design in a $5 \times 3$ factorial scheme, with three replications. The first factor studied was nitrogen rates $(40 ; 60 ; 80 ; 100$ and $120 \mathrm{~kg} / \mathrm{ha})$ and the second one was application time (30; 50 and 70 days after planting date (dap)). $\mathrm{N}$ rates and application time had a linear and independent effect over total garlic yield. Commercial yield decreased as $\mathrm{N}$ rates increased and the application of $40 \mathrm{~N} \mathrm{~kg} / \mathrm{ha}$ presented the highest commercial bulbs at $30 \mathrm{dap}(5,076 \mathrm{~kg} / \mathrm{ha}), 50$ dap $(5,502 \mathrm{~kg} / \mathrm{ha})$, and 70 dap $(4,086 \mathrm{~kg} / \mathrm{ha})$. Latest application resulted in the lowest commercial yield. Secondary growth bulbs increased linearly from 30.6 ; 34.9 , and $42,0 \%$ for $40 \mathrm{~N} \mathrm{~kg} / \mathrm{ha}$ to $65.2 ; 68.8$, and $64.8 \%$ for $120 \mathrm{~N} \mathrm{~kg} / \mathrm{ha}$, respectively, at 30; 50, and 70 dap. A linear effect on average weight of bulbs occurred due to $\mathrm{N}$ rates and application time of fertilizer, and the number of cloves increased with $\mathrm{N}$ increasing.
\end{abstract}

Keywords: Allium sativum L., yield, secondary growth bulbs, average bulb weight, number of cloves per bulb.

\section{(Aceito para publicação em 12 de abril de 2.001)}

$\mathrm{D}$ versos fatores têm sido relaciona dos com a ocorrência de pseudoperfilhamento em alho, sendo o nitrogênio considerado um dos mais importantes. A influência de níveis elevados de nitrogênio, associados ou não a outros fatores, no pseudoperfilhamento do alho, faz com que muitos produtores utilizem menor quantidade desse nutriente. Em alguns casos quando se faz a vernalização antes do plantio, a adubação nitrogenada em cobertura não tem sido feita, podendo causar redução da produtividade (Souza, 1990). O pseudoperfilhamento é considerado uma característica comercialmente indesejá- vel, depreciando o produto e reduzindo a produtividade (Burba, 1983).

Há diversos trabalhos mostrando os efeitos do $\mathrm{N}$ sobre a cultura do alho. Moon \& Lee (1985) não observaram diferenças entre as fontes de uréia e sulfato de amônio, contudo, a porcentagem de plantas com pseudoperfilhamento 